\title{
FORRAGEAMENTO EM ACHAEARANEA CINNABARINA LEVI 1963 (ARANEAE, THERIDIIDAE) E EVOLUÇÃO DA CAÇA EM ARANHAS DE TEIA IRREGULAR
}

\author{
Hilton Ferreira Japyassú \& Eduardo Gonçalves Jotta
}

Biota Neotropica v5 (n1a) - http://www.biotaneotropica.org.br/v5n1a/pt/abstract?article+BN003051a2005

Recebido em 07/12/2003

Aceito em 01/02/2005

Laboratório de Artrópodes, Instituto Butantan, Av. Vital Brazil 1500, 05503-900, São Paulo, SP, Brazil.

E-mail: japyassu@butantan.gov.br

\begin{abstract}
Orbweb monophyly and its evolution towards monophyletic irregular webs are a recent demonstration of the utility of behaviour on phylogenetic analyses. The loss of web regularity implies a change in prey signal reception by the spider, and therefore should be accompanied by changes in the hunting repertoire. We investigate this hypothesis by comparing hunting tactics in Achaearanea cinnabarina Levi 1963 with that of other theridiids and also with orbweavers. We have videotaped 40 captures of two prey taxa; the sessions have been transcribed with the program Observer Video Pro and afterwards analyzed with the program EthoSeq. Achaearanea cinnabarina hunting routines are extremely plastic, so that they probably will show a low level of taxonomic information. Nevertheless there is also a large number of context independent routines, routines which occur with both prey types, and these routines are probably useful for cladistic analysis. Achaearanea cinnabarina unconditionally uses the wrap-bite strategy, one that is used mainly towards dangerous prey among orbweavers. This is probably a result of evolutionary changes in the diet (ants are a major prey of theridiids), which in turn are probably the result of combined changes in web structure and website selection. Thus, the evolution of orbwebs to theridiid cobwebs resulted in a reduction of the hunting repertoire.
\end{abstract}

Key words: Araneae, Theridiidae, Achaearanea cinnabarina, foraging, evolution

\section{Resumo}

A monofilia da teia orbicular e sua evolução para teias irregulares, também monofiléticas, é um dos casos recentes que mostram a utilidade do comportamento em análises filogenéticas. A perda de regularidade da teia implica mudanças na recepção de sinais da presa, o que pode provocar alterações no repertório de caça. Investigamos esta hipótese comparando as estratégias de caça em Achaearanea cinnabarina Levi 1963 com a de outros teridídeos e também com orbitelas, discutindo assim a evolução do comportamento de caça no grupo. Filmamos 40 seqüências de captura de frente a dois tipos de presa; as seqüências foram transcritas com o auxílio do programa Observer Video-Pro e analisadas através do programa EthoSeq. As rotinas de caça em A. cinnabarina são extremamente plásticas, o que sugere serem caracteres com nível reduzido de informação taxonômica; por outro lado, um número expressivo de rotinas comportamentais independe do contexto, ocorrendo com ambos os tipos de presa, o que sugere serem úteis na análise cladística. A. cinnabarina se utiliza sempre da estratégia enrola-morde, uma estratégia que em orbitelas é utilizada principalmente frente a presas que oferecem risco à aranha. A adoção indiscriminada de uma estratégia para presas perigosas foi provavelmente selecionada pelo aumento na proporção deste tipo de presas (formigas), que por sua vez decorre de alterações evolutivas na estrutura da armadilha e na seleção de microhabitat. Assim, a transformação da teia orbicular em teia de lençol com sapatas adesivas, típica dos teridídeos, levou a uma simplificação do repertório de caça.

Palavras-chave: Araneae, Theridiidae, Achaearanea cinnabarina, forrageamento, evolução. 


\section{Introdução}

As aranhas apresentam uma grande variedade de armadilhas para a captura de suas presas. Teias em alçapão, lençóis recobrindo superfícies, lençóis aéreos, malhas tridimensionais irregulares, teias orbiculares: uma grande diversidade de estratégias que evoluíram para lidar com uma diversidade ainda maior de presas (Wise 1993). Some-se a isso o fato de que um mesmo padrão de teia pode ter surgido independentemente em diferentes grupos, e poderemos ter uma diversidade comportamental ainda maior entre as aranhas. As teias orbiculares, p.ex., podem ser construídas por aranhas com (Uloboridae, Deinopidae) ou sem cribelo (Araneidae, Tetragnathidae), o que levou alguns autores a sugerirem a homoplasia do padrão (a teia orbicular de Uloboridae não seria homóloga, por exemplo, à teia orbicular de Araneidae; Kullmann 1972).

Tais considerações colocam em questão a relevância dos padrões de comportamento para a compreensão das relações de parentesco, e a extrema variabilidade do comportamento leva muitos autores a sugerir que o comportamento não seja utilizado na reconstituição filogenética (Atz 1970, Brown 1975, Greene 1994, Proctor 1996). Muitos estudos, no entanto, têm mostrado que detalhes do comportamento são informativos de um ponto de vista filogenético (McLennan et al. 1988, Prum 1990, De Queiroz \& Wimberger 1993, Paterson et al. 1995, Slikas 1998), e em alguns casos estes detalhes de comportamento apresentam índices de consistência ainda melhores (menor nível de homoplasia) que os dos caracteres morfológicos (Scharff \& Coddington 1997). Em uma sucessão de trabalhos acerca da evolução do padrão de teia orbicular, Coddington e colaboradores mostram que a teia orbicular (e portanto todos os detalhes comportamentais utilizados na sua elaboração) é homóloga nos grupos de aranhas nos quais ocorre (Coddington 1986, 1990; Griswold et al. 1998). Além disso, mostram também que algumas aranhas construtoras de teia em lençol (Linyphiidae, Pimoidae) evoluíram a partir da teia orbicular e, posteriormente, originaram as teias com lençol irregular e com sapernas adesivas (Theridiidae, Nesticidae). Isto coloca uma questão interessante acerca dos outros aspectos do comportamento destas aranhas: se a construção da teia mudou radicalmente nestes grupos, será que outros comportamentos associados também se alteraram? Uma segunda questão seria: se os detalhes do comportamento são filogeneticamente informativos, o que dizer de comportamentos mais molares, de encadeamentos longos de unidades comportamentais?

O presente estudo discute estas questões com base no comportamento predatório da aranha Achaearanea cinnabarina Levi 1963 (Theridiidae; Fig. 1), uma espécie desconhecida do ponto de vista de sua biologia. Theridiidae é uma das mais diversas famílias de aranhas, com 2209 espécies distribuídas em 80 gêneros (Platnick 2004). Recentemente Benjamin \& Zschokke (2003) descreveram a estrutura e a construção da teia em vários teridídeos, além de realizarem uma compilação da literatura disponível até o momento, identificando 4 tipos básicos de teia nesta família. Apesar destes esforços, a amostragem de espécies com tipo de teia conhecida ainda é extremamente insatisfatória (29spp. de um total de 2209), o que deixa claro que a diversidade de arquiteturas das teias e de outros aspectos do comportamento de teridióideos é ainda pouco conhecida (Griswold et al. 1998). Novas informações neste sentido são necessárias para uma visão mais abrangente acerca da evolução da teia orbicular para as teias em lençol e destas para aquelas com sapatas adesivas, e o presente estudo pretende ser uma contribuição neste sentido, procurando introduzir nesta discussão a questão da evolução das seqüências predatórias nas aranhas orbitelas, bem como a questão mais geral da evolução da plasticidade presente em estratégias comportamentais ajustáveis ao contexto.

\section{Material e Métodos}

Foram coletadas na Mata da CUASO (Instituto de Biociências - USP-SP) 20 fêmeas adultas de Achaearanea cinnabarina. No laboratório as aranhas foram colocadas em caixas de acrílico transparente $(14,5 \times 15 \times 15 \mathrm{~cm}) \mathrm{com}$ fundo de poliestireno preto fosco. Os indivíduos eram alimentados semanalmente com ninfas de Gryllus sp. As filmagens foram realizadas sob luz branca lateral e contra um fundo escuro, sempre por duas pessoas, uma das quais descrevendo a seqüência. Foi utilizada uma câmera digital Cannon XL1 e um tripé.

Cada aranha foi filmada duas vezes, uma capturando formiga saúva (Atta sp) e outra capturando larva do besouro Tenebrio molitor. A seleção destes dois táxons teve por finalidade amostrar uma grande diversidade dentro do repertório predatório da aranha, dado serem presas muito diferentes quanto ao formato geral do corpo, ao seu comportamento, ao nível de agressividade (p.ex., observamos frequenctemtne em laboratório formigas Atta sp amputando a perna de uma aranha orbitela - Metazygia rogenhoferi Keyserling 1878 - enquanto a aranha tentava capturá-la). Além disso tais presas oferecem diferenças também quanto à experiência prévia da aranha com cada uma delas; vários estudos mostram que formigas são ítens alimentares freqüentes, podendo compor até 75\% da dieta de teridídeos (Holldobler 1970, Carico 1978, MacKay 1982, Nyffeler \& Benz 1987, Nyffeler et al. 1988, Breene et al. 1989, 1993), enquanto que as larvas compõem apenas $2 \%$ da dieta dessas aranhas (Riechert \& Luczak 1982).

O forrageamento em aranhas varia em função de variáveis ambientais (v. ref. em Japyassú \& Viera 2002), portanto alguns parâmetros foram controlados para reduzir tal interferência. Assim, as filmagens das capturas foram realizadas dentro das seguintes condições: (1) no sétimo dia após alimentação, de forma a manter o mesmo nível de saciedade 


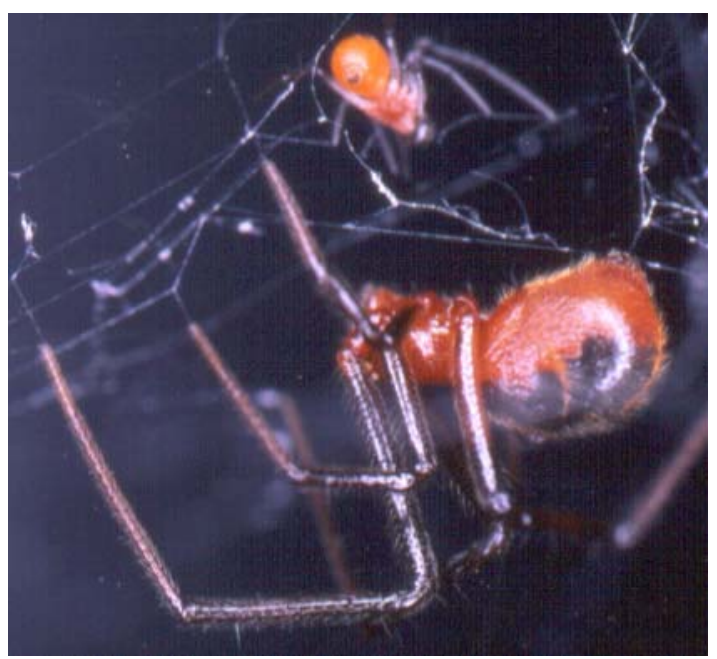

Figura 1. Fêmea e macho (menor) de Achaearanea cinnabarina (foto de Hylio Lagana).

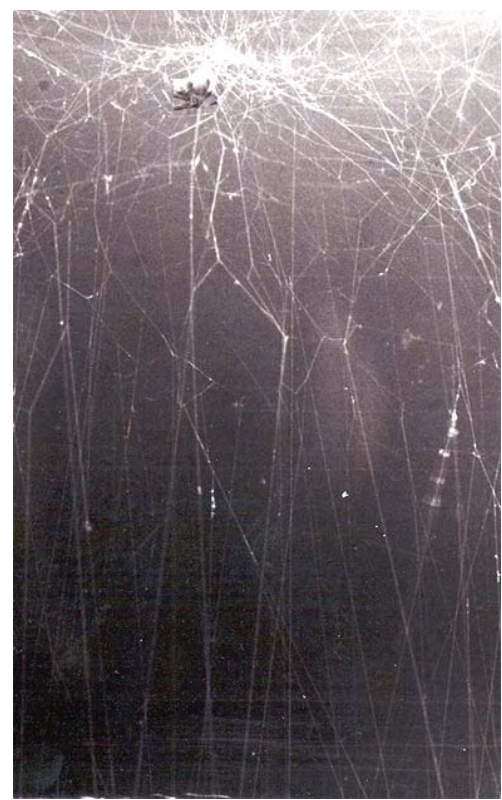

Figura 2. Teia de A. cinnabarina. Aranha na porção superior, mais densa, onde se situa o lençol da teia. Do lençol partem fios verticais (fios âncora) para o substrato inferior. No ponto de fixação dos fios âncora ao substrato existe uma série de gotículas adesivas (sapatas adesivas, não visível; foto de EGJ). 


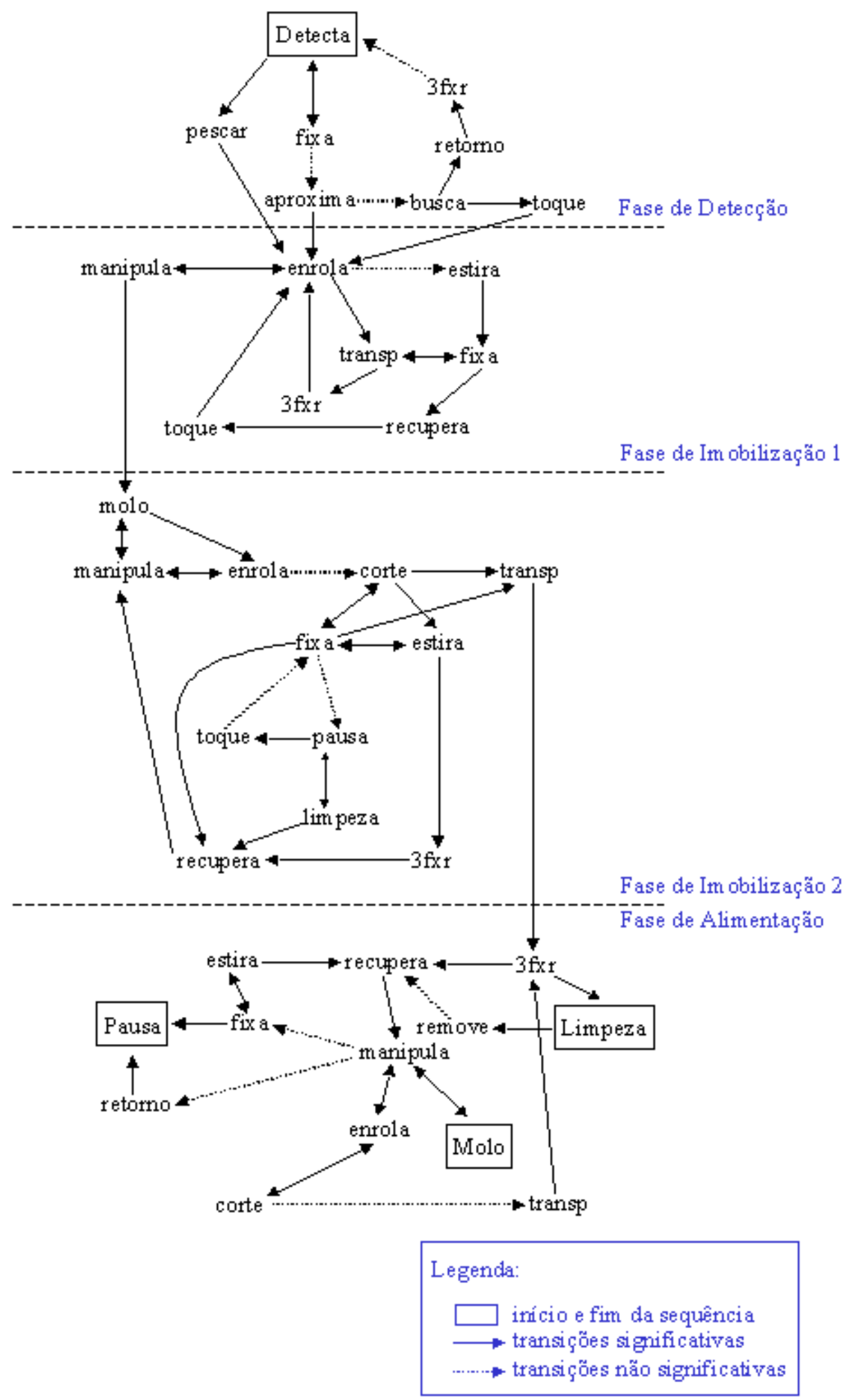

Figura 3. Etograma da captura de larvas do besouro Tenebrio molitor. Para descrições das categorias comportamentais, veja o anexo 1. 


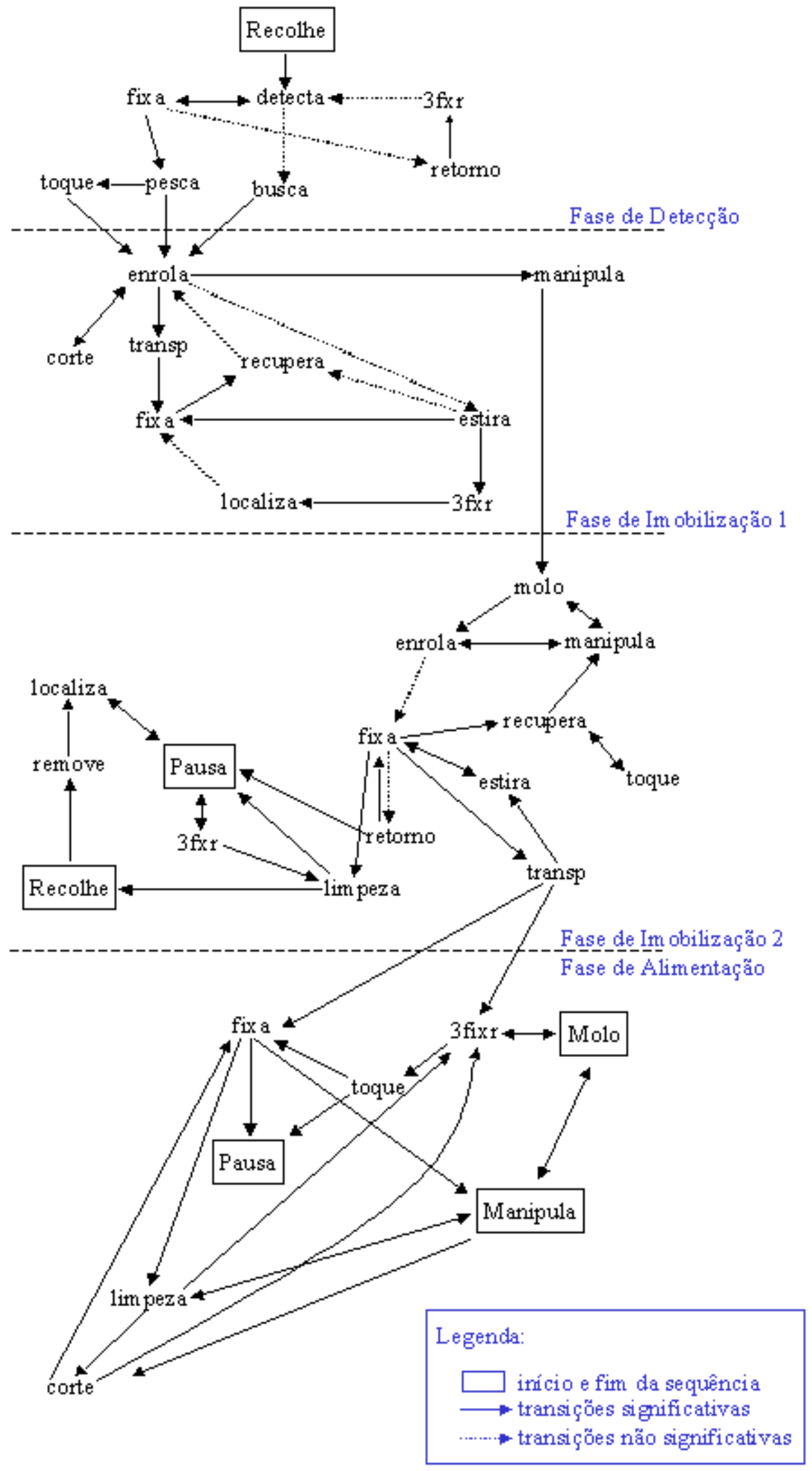

Figura 4. Etograma da captura de formigas (Atta sp). Para descrições das categorias comportamentais, veja o anexo 1. 


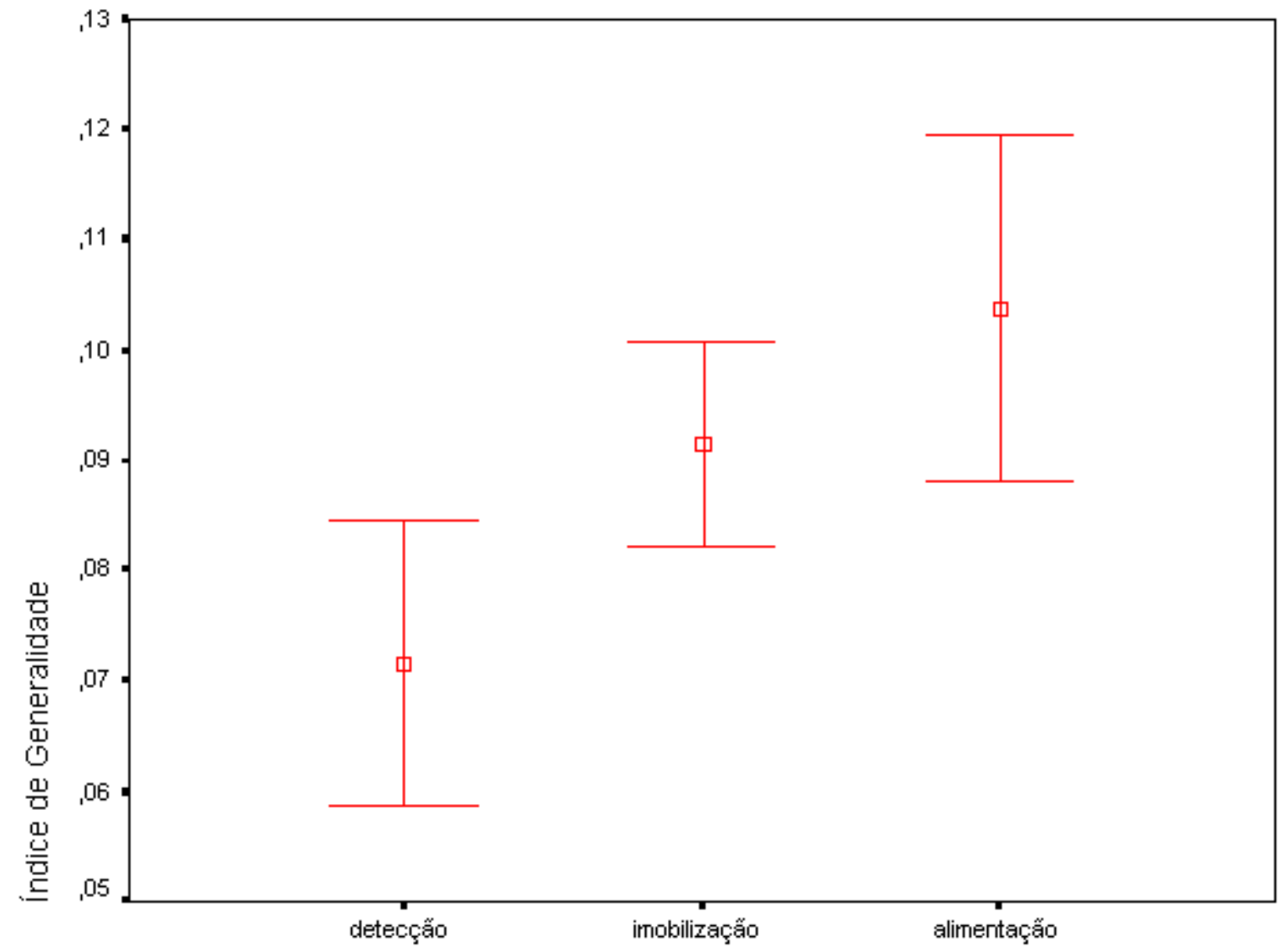

Fase na Seqüência Predatória

Figura 5. Grau de estereotipia (Índice de Generalidade) nas sucessivas fases da seqüência predatória de A. cinnabarina. 


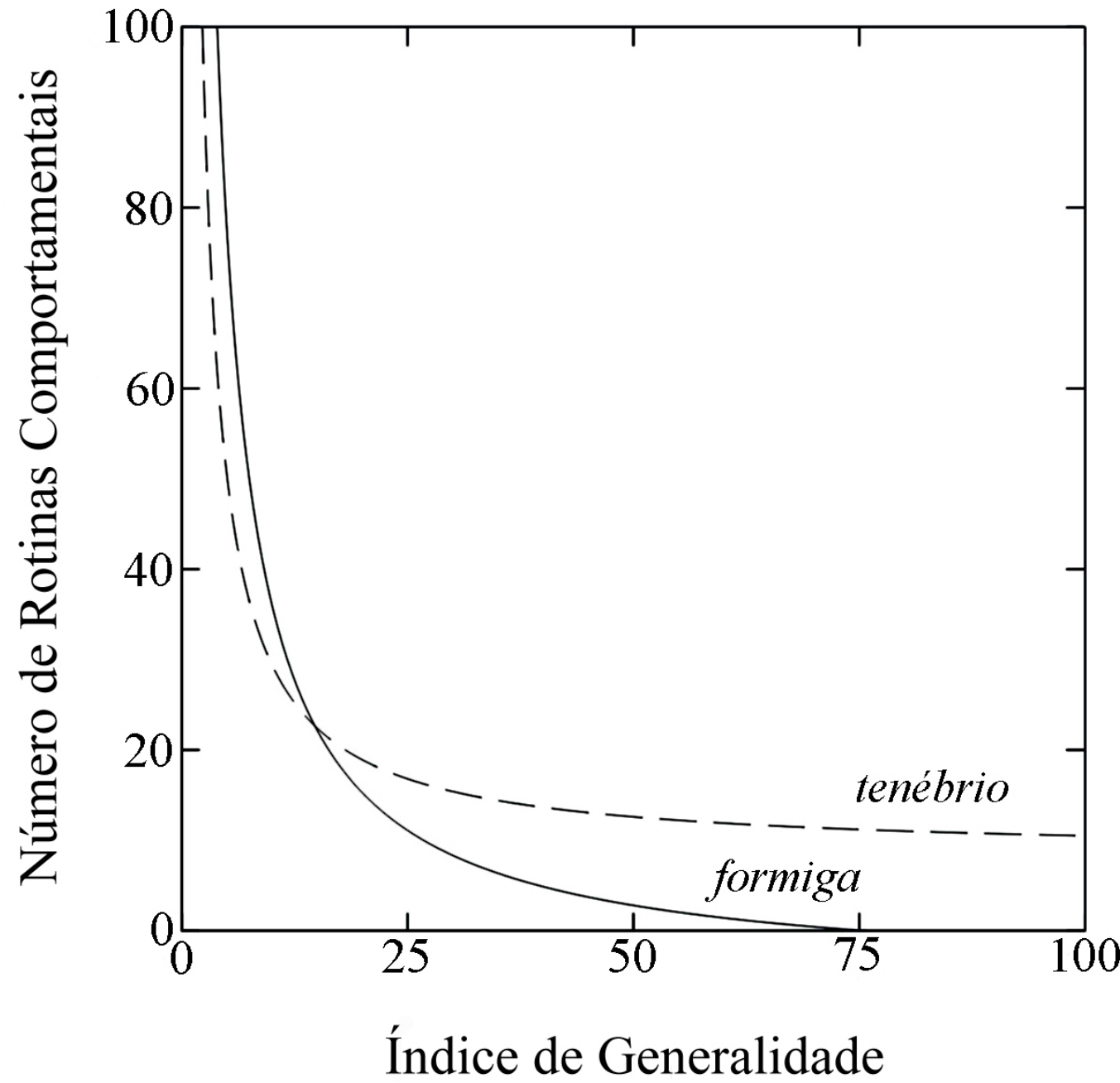

Figura 6. Curva de distribuição do grau de estereotipia (Índice de Generalidade) na captura de tenébrios (linha pontilhada) e formigas (linha cheia).

\begin{tabular}{|l|c|c|}
\hline & $\mathrm{N}^{0}$ de Rotinas & Porcentagem das Rotinas \\
\hline Rotinas exclusivas Formiga & 247 & 26,2 \\
\hline Rotinas exclusivas Tenébrio & 363 & 38,4 \\
\hline Rotinas em comum & 335 & 35,4 \\
\hline Total & 945 & 100 \\
\hline
\end{tabular}


para todas as aranhas; (2) sempre no período da tarde, de modo a se padronizar o momento no ciclo circadiano das aranhas (embora os teridídeos capturem presas a qualquer momento do dia, aranhas apresentam ritmicidade circadiana em aspectos de seu forrageamento - v. p.ex. Valle \& Valle (1972) -, o que poderia introduzir pequenas variações temporais na caça); (3) num intervalo de 15 a 30 dias após a construção da teia, pois a densidade de fios aumenta com o tempo; (4) com presa de tamanho aproximadamente igual ao do corpo da aranha (cefalotórax e abdome). A seqüência predatória foi dividida em três fases sucessivas, seguindo proposição de Viera (1986, 1994): (1) fase de detecção - do início da seqüência até imediatamente antes do contato com a presa (que se dá através do enrolamento com seda viscosa); (2) fase de imobilização que se inicia com o enrolamento com seda viscosa e termina com o transporte da presa ao refúgio, e (3) fase de alimentação - que compreende os últimos cinco minutos de cada seqüiência, com a presa imobilizada no refúgio (no caso de A. cinnabarina não há propriamente um refúgio, mas há claramente uma região central superior do lençol na qual a aranha permanece).

Exemplares testemunho foram depositados na coleção sistemática do Laboratório de Artrópodes, Instituto Butantan (curador A.D. Brescovit) sob os números IBSP (25906, 25910, 27661, 27665, 27669, 27671, 27676, 32363, 32364e 34747).

\subsection{Análise das seqüências comportamentais}

As fitas de vídeo foram transcritas através do sistema observacional “Observer Vídeo Pro” (Noldus et al. 2000). As sessões transcritas foram transformadas em matrizes diádicas de transição (matriz antecedente-consequente, ou matriz de primeira ordem). Para se comparar a freqüência das categorias comportamentais frente aos diferentes ítens alimentares, foram utilizados testes não paramétricos (Wilcoxon Signed Ranks). Para a construção dos etogramas, foram utilizadas apenas as transições significativas $(\mathrm{P}<0,05)$ após análises através do qui-quadrado de Clark (1994; foram desconsideradas as diagonais da matriz).

Para a detecção de rotinas comportamentais longas (seqüências de três ou mais categorias) foi utilizado o programa EthoSeq ${ }^{1}$ (Japyassú et al., no prelo). O programa EthoSeq produz uma representação hierárquica (árvore orientada), na qual cada categoria comportamental aparece como um nó, sendo o nó basal denominado raiz. Cada matriz resulta em tantas árvores orientadas quanto o número de categorias existentes (cada categoria é utilizada uma vez como raiz). Depois de escolhida a primeira categoria comportamental da árvore (raiz), as categorias seguintes serão as que tiverem as maiores probabilidades de suceder tal raiz (na matriz diádica de transição); este procedimento de busca das categorias mais prováveis se repete até que todas as categorias estejam incluídas na árvore orientada. Cada árvore apresenta raiz, galhos e folhas, e as seqüências de categorias da raiz até uma folha, se tiverem ocorrido nos dados originais, são as rotinas comportamentais (Japyassú et al., no prelo, Japyassú \& Vieira 2002).

Para a análise da estereotipia foi criado um índice que mede o quanto as seqüências de captura são semelhantes quando as aranhas são expostas a um mesmo tipo de presa. Este Índice de Generalidade (IG) é calculado através da divisão do número de capturas nas quais ocorreu uma determinada rotina comportamental pelo número total de capturas amostradas.

\subsection{Cuidado parental}

Quatro indivíduos com ootecas foram observados em laboratório. Após a eclosão, as aranhas eram alimentadas semanalmente com ninfas de Gryllus sp (de tamanho semelhante ao da aranha - entre 0,5 e $0,9 \mathrm{~cm}$ ) e a seqüência predatória era observada até a total imobilização da presa e o início da ingestão, registrando-se eventuais participações dos filhotes na captura da presa. Estando a presa capturada, eram feitas observações ad libitum de cinco minutos a cada hora, durante quatro horas, para se verificar se os filhotes se alimentavam da presa juntamente com a mãe. Para a análise da dispersão dos filhotes, foi registrada semanalmente a quantidade de filhotes que ficavam junto à mãe até que o último filhote abandonasse a teia.

\section{Resultados}

\subsection{Cuidado Parental e Dispersão dos Filhotes}

A mãe não permite que os filhotes participem da captura das presas. Quando os filhotes tentam interferir na captura, a mãe os expulsa, empurrando os filhotes com uma de suas pernas (4 episódios em um total de 15 observações). No entanto, as mães alimentam seus filhotes, permitindo sua aproximação quando a presa está totalmente imobilizada, próxima a ou dentro do refúgio (em 14 dos 15 casos observados os filhotes se alimentaram em grupo, juntamente com a mãe). Algumas vezes, ao retornar à presa armazenada para dela se alimentar, a mãe expulsa um filhote do grupo que estava se alimentando (2 eventos em 15).

Em relação às interações entre os filhotes, só foi observada alguma agressividade quando os filhotes tentavam se alimentar da presa muito próximos um do outro. Nestes casos (2 eventos em 15), o filhote maior ficava se alimentando e o outro se afastava, sem interferência da mãe.

\footnotetext{
${ }^{1}$ O programa EthoSeq permite a análise estatística de transições de primeira ordem e a análise probabilística de transições de ordens superiores. Ele foi desenvolvido por uma equipe multidisciplinar de pesquisadores (Unesp-Assis, IPUSP-SP, IF-UFSCar, IBut) e está disponível diretamente com o autor.
} 
Os filhotes ficaram junto à mãe entre a segunda e a terceira muda. Em um dos casos, a mãe morreu antes da dispersão dos filhotes, e a maioria dos filhotes que estavam com essa aranha também morreu em seguida.

\subsection{Descrição da Teia}

A teia da A. cinnabarina (fig. 2) é do tipo Achaearanea (Benjamin \& Zschokke 2003), constituindo-se em um lençol superior irregular, de onde saem fios âncora com sapernas adesivas em sua base, os quais se fixam ao solo e às laterais do local de construção da teia. O lençol apresenta uma região central com uma maior densidade de fios, onde as aranhas habitualmente colocam folhas dobradas para formar o seu refúgio. Mesmo na ausência de folhas (nas caixas acrílicas do laboratório) as aranhas constróem normalmente sua teia, mas não adicionam qualquer estrutura sedosa diferenciada como refúgio. A aranha permanece na região central do lençol, em sua face inferior.

\subsection{Comportamento de Captura}

Nas seqüências predatórias ocorreram 19 categorias comportamentais. As descrições destas categorias comportamentais (detecção, aproximação, pesca, enrolamento, toque, mordida, manipulação, fixação, estiramento, corte de fios, retorno, transporte, fixações com rotação, limpeza, busca, recuperação, pausa, localização, remoção) são apresentadas no anexo 1 .

Embora a captura de formiga seja geralmente mais demorada (média=1350") que a de tenébrio (média=962"; Z= 2,651; $\mathrm{P}=0,008 ; \mathrm{N}=20$ ), as aranhas foram mais ativas (realizaram um número maior de categorias comportamentais por captura) frente ao tenébrio que frente às formigas $(\mathrm{Z}=-2,650 ; \mathrm{P}=0.008$; $\mathrm{N}=20$ ). Com formigas as aranhas concluíram a captura com um número de categorias que variou entre 35 e 55; já com tenébrios essa variação foi de 60 a 90 categorias/captura.

\subsubsection{Etogramas da captura}

A aranha inicia a captura de tenébrio (fig. 3) a partir do refúgio, na fase de detecção (veja no apêndice a descrição das categorias). Inicialmente ela alterna curtos deslocamentos no lençol (c.5mm) seguidos de tensionamentos dos fios com o primeiro par de pernas (detecta) com fixações de fios no lençol da teia. Ao tocar no fio âncora onde se encontra presa, a aranha desce por ele (aproxima) para começar a imobilizar a presa com enrolamentos; nesta imobilização os fios são inicialmente viscosos (enrolamento de captura) e posteriormente secos (enrolamento - esta diferença de viscosidade é facilmente perceptível com boa iluminação, fundo escuro, e uma lupa de mão). A partir deste ponto, começa a fase de imobilização, quando a aranha alterna repetidamente três comportamentos: enrolamento, manipulação e mordidas na presa (tríade de imobilização - TrI). A aranha inicia a liberação da presa da teia (corte de fios), fixa um novo fio à presa e desloca-se em direção ao refúgio, deixando atrás de si um fio guia (estira); ela então fixa na teia e retorna à presa (recupera) para nova compactação da presa (via TrI). Esta macro-seqüência TrI-estira/recupera-TrI se repete algumas vezes até que se inicie o transporte; chegando ao refúgio (fase de alimentação) a aranha armazena a presa (3fxr), apenas para recuperá-la, manipulá-la e posteriormente, nela aplicar uma mordida final.

Assim como na captura de tenébrio, a captura de formiga (fig. 4) se inicia com detecções alternadas com fixações, no lençol da teia. Ao invés de descer pelo fio âncora (onde está a presa) assim que o localiza, a aranha pesca este fio e começa a enrolar a presa (inicialmente com seda viscosa), iniciando a fase de imobilização. Seguem-se depois várias manipulações, para uma posterior mordida. Como em tenébrio, a aranha realiza a macro-seqüência TrI-estira/recupera-TrI, só que agora ela às vezes interrompe esta macro-seqüência para iniciar surtos de limpeza alternados com pausas. É durante a macro-seqüência que a aranha pode inicia o transporte da presa ao refúgio, o que freqüentemente se dá por aproximações sucessivas: como a presa pode ficar enroscada no lençol durante o transporte, a aranha retorna à macro-seqüência para nova compactação da presa, e depois retoma o transporte (isto se repete até que a presa chegue ao refúgio, iniciando a fase de alimentação). Chegando ao refúgio, a aranha fixa fios enquanto se volta para a presa $(3 f x r)$ para tocá-la e terminar a captura em uma longa pausa.

\subsubsection{Rotinas comportamentais}

As descrições acima correspondem ao tipo de captura mais freqüente nesta aranha. A inspeção das figuras 3 e 4 mostra, no entanto, que existem muitos outros caminhos possíveis no fluxograma, ou seja, mostra que existe uma grande variabilidade na seqüência de captura. Esta variabilidade pode ser quantificada através da análise das rotinas comportamentais.

O repertório empregado na captura de tenébrios é mais amplo que o utilizado na captura de formigas (tenébrio: 698 rotinas comportamentais e formiga: 582). A fase de imobilização é a mais diversificada comportamentalmente (794 rotinas; detecção, 221 e alimentação 387 rotinas).

Várias rotinas comportamentais são utilizadas com ambas as presas (rotinas comuns) enquanto que outras são utilizadas exclusivamente com um ou outro táxon (rotinas exclusivas); a captura de tenébrio envolve um número maior de rotinas exclusivas que a captura de formiga. A porcentagem de rotinas comuns presentes na captura das presas oferecidas (índice de comunalidade) foi de 35,4\% (Tab. 1). 
As rotinas mais freqüentes utilizadas exclusivamente na captura de tenébrio estão relacionadas principalmente com a imobilização e o preparo da presa para o transporte ao refúgio. Já as rotinas mais freqüentes utilizadas exclusivamente na captura de formigas ocorreram principalmente no início da captura, na fase de detecção.

\subsubsection{Estereotipia no comportamento predatório}

No decorrer da captura, o comportamento se torna cada vez mais estereotipado; o índice de generalidade (IG) é menor na fase de detecção, e atinge o maior grau na fase de alimentação ( $N=1438 ; c^{2}=6,921 ; P=0,031$; fig. 5). A captura de tenébrios é, em média, tão estereotipada quanto a de formigas ( $U=192132.50 ; \mathrm{P}=0.57 ; \mathrm{N}=1281$ ).

Apesar desta semelhança no grau médio de estereotipia na captura dos dois tipos de presa, a análise detalhada da distribuição do IG das 945 rotinas comportamentais (obtidas pelo programa EthoSeq - Tab. 1 e Fig. 6) mostra que tal semelhança não ocorre em todos os pontos da distribuição. Para ambas as presas há uma enorme quantidade de rotinas pouco estereotipadas, ou seja, rotinas realizadas por poucas aranhas (menos de 25\% da amostra, ou seja, menos de 5 aranhas). Entre estas rotinas pouco estereotipadas (que são a imensa maioria do total de rotinas obtidas) não há mesmo uma diferença clara entre o índice de estereotipia da captura de tenébrio e de formiga (as duas curvas na figura 6 praticamente se sobrepõem nesta faixa). Se nos concentrarmos agora nas rotinas mais estereotipadas (realizadas por mais de 50\% da amostra), veremos que este número é muito pequeno: são poucas as rotinas que foram realizadas por várias das aranhas amostradas. No entanto, estas rotinas mais estereotipadas são mais freqüentes na captura de tenébrios que na captura de formigas.

\section{Discussão}

\subsection{Cuidado Parental e Dispersão dos Filhotes}

Os filhotes recém-nascidos, no caso de aranhas solitárias, costumam ficar junto à mãe até aproximadamente a segunda muda (Foelix, 1982). No caso de aranhas subsociais, os filhotes podem também se dispersar na segunda muda, mas a maioria permanece com a mãe por mais tempo, até a quarta ou quinta muda. Já nas aranhas sociais os filhotes não dispersam até a fase adulta (Jones \& Parker 2000). A dispersão tardia, como ocorre nas aranhas subsociais, pode trazer benefícios à mãe e aos filhotes, pois possibilita a captura de presas maiores e reduz o gasto individual de energia no reparo da teia e em outras atividades (Li et al. 1999, Kim 2000).

No caso de A. cinnabarina, que é uma aranha solitária, a dispersão ocorre mais cedo, entre a segunda e a terceira muda, que é justamente o momento em que os filhotes iniciam a captura de presas (Kim 2000). Os filhotes de A. cinnabarina apenas se alimentam das presas previamente capturadas pela mãe, trazendo um prejuízo energético para a mesma, já que esta deve alimentar a si e aos filhotes. Como os filhotes dispersam logo que estão aptos a capturar presas sozinhos, o investimento energético feito pela mãe não é compensado pelos filhotes, como no caso das aranhas subsociais e sociais.

Kim (2000) sugere que o aumento de agressividade entre os filhotes é um dos fatores que influenciam a dispersão. No caso de A. cinnabarina, eventos de agressividade entre filhotes foram muito raros, de modo que a dispersão dos filhotes não parece ser explicada por este fator. É provável que outros fatores, tais como a redução relativa na oferta de alimento (à medida que os filhotes crescem, precisam de cada vez mais alimento), seja uma dica proximal relevante para o início da dispersão.

\subsection{Estratégias de Captura}

A. cinnabarina usa como áreas de captura tanto o lençol quanto os fios âncora com sapatas adesivas fixados ao solo e à vegetação próxima, o que possibilita a captura de diversos tipos de presa, tanto presas voadoras quanto cursoriais (no laboratório, a aranha captura drosófilas no lençol de sua teia). As espécies pertencentes à família Theridiidae se alimentam principalmente de insetos, sendo que as principais ordens presentes em sua dieta são Hymenoptera, Homoptera, Diptera e Coleoptera, e a diversidade na dieta permite que as aranhas mantenham uma dieta equilibrada em termos nutricionais (Nyffeler 1999).

A. cinnabarina inicialmente enrola a formiga e depois morde uma de sua pernas, sempre longe da cabeça. MacKay (1982) também observou em teridídeos uma estratégia de captura diferenciada para formigas, estratégia esta que reduz os riscos de injúria para a aranha. A captura de tenébrio é mais rápida que a de formigas. Como este tipo de presa não oferece risco à aranha, ela leva o tenébrio rapidamente para o refúgio. Já a formiga tenta se libertar usando pernas e mordendo os fios com a mandíbula, o que representa risco para a aranha (durante a captura, Metazygia rogenhoferi Keyserling 1878 autotomiza pernas mordidas por formigas, C. Garcia, comunic.pess.), tornando vantajosa a estratégia freqüentemente adotada por A. cinnabarina de só levar a formiga para o refúgio quando esta se encontra paralisada.

O tamanho das presas também pode ser um fator que altere o comportamento da aranha (Japyassú \& Viera 2002). Por serem um pouco maiores, os tenébrios requerem uma maior freqüência de enrolamentos e, consequentemente, um número também maior de fixações na presa (categoria que geralmente finaliza um surto de enrolamento). O maior peso do tenébrio pode dificultar o transporte, o que explicaria o fato de a aranha realizar um grande número de pequenos e sucessivos transportes parciais com tenébrio, os quais são seguidos de recuperações da presa (categorias estas menos freqüentes na captura de formigas). 
Apesar da diversidade de estratégias descritas, $A$. cinnabarina sempre se utiliza do enrolamento com fio viscoso como primeira atividade antes do contato com a presa, no que parece ser uma estratégia para lidar com presas perigosas, já que o contato direto com a presa só ocorre após a imobilização por enrolamento. Aranhas orbitelas (das quais teridídeos são evolutivamente derivados) apresentam uma maior diversidade comportamental neste primeiro contato e, entre suas formas de abordagem à presa, sempre está presente uma estratégia de contato direto por mordida (morde-enrola; Peters 1931 apud Robinson 1975, Ades 1972, Robinson 1975, Lubin 1980, Viera 1994). Assim, o estudo da captura de presas em A. cinnabarina corrobora a hipótese de que, ao longo da evolução, os teridídeos teriam simplificado seu repertório de caça, eliminando algumas das estratégias presentes nas orbitelas (Japyassú \& Caires, subm.). É significativo que tal mudança esteja associada a uma mudança estrutural importante na armadilha: o surgimento das sapatas adesivas (v. Griswold et al. 1998). As sapatas adesivas promoveram uma importante alteração na dieta destas aranhas, que passa a incluir presas cursoriais, entre as quais prevalecem as formigas (Holldobler 1970, Carico 1978, MacKay 1982, Nyffeler \& Benz 1987, Nyffeler et al. 1988, Breene et al. 1989, 1993; Hódar \& Sanchez-Piñero 2002). Parece provável que a estratégia de captura defensiva dos teridídeos tenha sido selecionada pela inclusão em sua dieta de presas abundantes e potencialmente perigosas.

\subsection{Estereotipia no comportamento predatório}

O conceito clássico de estereotipia está primariamente associado à noção de padrão fixo, de controle endógeno, de comportamento típico da espécie (Lorenz 1970) e, neste sentido, se assemelha aos caracteres diagnósticos utilizados em taxonomia alfa (características morfológicas que permitem a identificação de um táxon, utilizadas tradicionalmente na descrição de uma espécie). O presente estudo mostra que dentro do repertório predatório de A. cinnabarina são poucos os comportamentos realizados por todas as aranhas (fig. 6), são poucas as rotinas que atingem o nível de homogeneidade dentro da espécie que pressupõe o conceito clássico de estereotipia.

A seqüência predatória está mais afeita à noção de um programa comportamental (sensu Ades 1986). Suas unidades constituintes (categorias comportamentais) poderiam ser comparadas a comportamentos estereotipados (no sentido clássico do termo), mas a concatenação destas unidades, formando as seqüências predatórias propriamente ditas, não está sob o controle de um estímulo eliciador único (p. ex., a presa caindo na teia) que determina toda a seqüência restante. Não parece haver uma estruturação endógena completa da seqüência predatória, mas sim uma estruturação de pequenas unidades, as quais estão organizadas seqüencialmente de forma probabilística. A topologia precisa dos acontecimentos é probabilística, dependendo tanto de uma organização interna como de uma leitura constante dos estímulos provenientes da presa. À medida que a presa deixa de reagir, à medida que ela vai sendo imobilizada, a estereotipia no comportamento da aranha aumenta (fig. 5), o que mostra que a variabilidade das respostas da presa é um dos fatores que entram na determinação da seqüência de captura: à medida que diminuem os graus de liberdade da presa, aumenta a previsibilidade do comportamento da aranha.

\section{Conclusões}

A evolução da estrutura da armadilha das aranhas orbitelas teve conseqüências tanto para a topologia das seqüências de captura quanto para a amplitude do repertório de caça. Nossos resultados sugerem que a transformação da teia orbicular em teia de lençol com sapatas adesivas, típica dos teridídeos, levou a uma simplificação do repertório de caça nestas aranhas, que perderam a capacidade, por exemplo, de capturar uma presa através da seqüência mordeenrola. A. cinnabarina se utiliza sempre da estratégia enrolamorde, uma estratégia que em orbitelas é utilizada frente a presas que oferecem risco à aranha. A adoção indiscriminada de uma estratégia para presas perigosas foi provavelmente selecionada pelo aumento na proporção deste tipo de presas (formigas), que por sua vez decorre de alterações evolutivas na estrutura da armadilha e na seleção de microhabitat.

Com relação ao uso de seqüências predatórias para a reconstrução de filogenias, nossos resultados se mostram ambíguos. De um lado, o alto grau de plasticidade verificado (IGs baixos) sugere que as rotinas comportamentais são caracteres com nível reduzido de informação taxonômica. De outro lado, um número expressivo de rotinas comportamentais não depende do contexto, ocorrendo com ambos os tipos de presa, o que sugere que tais rotinas seriam bons candidatos para uma análise cladística. Para se resolver tal ambigüidade faz-se necessária uma exploração da correlação entre o grau de plasticidade comportamental e o índice de consistência das rotinas nas filogenias obtidas.

\section{Agradecimentos}

Este trabalho não teria sido possível sem a constante ajuda de Cátia Regina Macagnan e Ana Maria Macedo, tanto no cuidado com as aranhas quanto no olho clínico para destrinchar comportamentos. Agradeço também as críticas e comentários de dois pareceristas anônimos. Apoio: Fapesp (99/04442-9 e 99/05446-8) e Fundap.

\section{Referências Bibliográficas}

ADES, C. 1972. A teia e a caça de Argiope argentata. Tese de Doutorado. Instituto de Psicologia. Universidade de São Paulo. Vols. 1 e 2. 
ADES, C. 1986. A construção da teia geométrica como programa comportamental. Ciência e Cultura 38(5): 760-775.

ATZ, J.W. 1970. The application of the idea of homology to behavior. In: Development and Evolution of Behavior (L. R. Aronson, E. Tobach, D. S. Lehrman \& J. S. Rosenblatt, eds.). Freeman, San Francisco, p. 53-74.

BREENE, R. G., STERLING, W. L. \& DEAN, D. A. 1989. Spider and ant predators of the cotton fleahopper on wooly croton. Southwest. Entomol. 13: 177-183.

BREENE, R.G., MEAGHER, R.L. Jr., \& DEAN, D.A. 1993. Spiders (Araneae) and ants (Hymenoptera: Formicidae) in Texas sugarcane fields. Florida Entomol. 76:645-650.

BROWN, J. 1975. The Evolution of Behavior. W. W. Norton, New York.

CARICO, J.E. 1978. Predatory behavior in Euryopis funebris (Hentz) (Araneae: Theridiidae) and the evolutionary significance of web reduction. Symposia of the Zoological Society of London 42: 51-58.

CLARK, D.L. 1994. Sequence analysis of courtship behavior in the dimorphic jumping spider Maevia inclemens (Araneae, Salticidae). J. Arachnol. 22, 94-107.

CODDINGTON, J.A. 1986. The monophyletic origin of the orb web. In: Spiders: webs, behavior, and evolution. 1st ed. (Ed: WA Shear) Stanford University Press, Stanford, p.319-363.

CODDINGTON, J.A. 1990. Ontogeny and homology in the male palpus of orb-weaving spiders and their relatives, with comments on phylogeny. Smithsonian contributions to zoology 496, 1-52.

FOELIX, R.F. 1982. The Biology of Spiders. Harvard University Press. Cambridge.

GRAY, M.R. \& ANDERSON, G.J. 1989. A new species of Argiope Simon (Aranoidea: Theridiidae) which preys on its host. Proceedings of the Linnean Society of New South Wales 111(1), 25-30.

GREENE, H.W. 1994. Homology and behavioral repertoires. In: Homology: The Hierarchical Basis of Comparative Biology (B. K. Hall, ed), pp. 369-391. Academic Press, San Diego.

GRISWOLD, C.E., CODDINGTON, J.A., HORMIGA, G. \& SCHARFF, N. 1998. Phylogeny of the orb-web building spiders (Araneae, Orbiculariae: Deinopoidea, Araneoidea). Zoological Journal of the Linnean Society 123, 1-99.

HÓDAR, J.A. \& SANCHEZ-PINERO, F. 2002. Feeding habits and web structure of Latrodectus lilianae (Araneae: Theridiidae) in an arid zone of southeast Spain. J. Zool. Lond. 257, 101-109.

HODGE, M.A. \& MARSHALL, S.D. 1996. An experimental analysis of intraguild predation among 3 genera of webbuilder spiders: Hipochilus. Coras and Achaearanea. Journal of Arachnology 24(2), 101-110.
HOLLDOBLER, B. 1970. Steatoda fulva (Theridiidae), a spider that feeds on harvester ants. Psyche 77: 202-208.

JACKSON, R.R. \& BRASSINGTON, R.J. 1987. The biology of Pholcus phalangioides (Araneae, Pholcidae): predatory versatility, araneophagy and agressive mimicry. $J$. Zool., London, 221: 227-238.

JAPYASSÚ, H.F. \& MACAGNAN, C.R. no prelo. Fishing for prey: the evolution of a new predatory tactic among spiders (Araneae, Pholcidae). Revista de Etologia.

JAPYASSÚ, H.F. \& VIERA, C. 2002. Predatory plasticity in Nephilengys cruentata (Aranaee: Tetragnathidae): relevance for phylogeny reconstruction. Behaviour 139: 529-544.

JAPYASSÚ, H.F., ALBERTS, C.C., IZAR, P. \& SATO, T. no prelo. EthoSeq: a tool for phylogenetic analysis and data mining on behavioural sequences. - Behavior Research Methods.

JAPYASSÚ, H.F. \& CAIRES R.A. (subm.) Hunting tactics in a cobweb spider (Araneae - Theridiidae) and the evolution of behavioral repertoires. Journal of Insect Behavior.

JONES, T.C. \& PARKER, P.G. 2000. Costs and benefits of foraging associated with delayed dispersal in the spider Anelosimus studiosus (Araneae, Theridiidae). The Journal of Arachnology 28, 61-69.

KIM, K.W. 2000. Dispersal behaviour in a subsocial spider: group conflict and the effect of food availability. Behavioral Ecology and Sociobiology 48, 182-187.

KULLMANN, E.J. 1972. The convergent development of orb-webs in cribellate and ecribellate spiders. Am.Zoologist 12, 395-405.

LEVI, H.W. 1963. American spiders of the genus Achaearanea and the new genus Echinotheridion (Araneae, Theridiidae). Bull. Mus. comp. Zool. Harv. 129: 187-240.

LI, D., JACKSON, R.R. \& BARRION, A.T. 1999. Parental and predatory behaviour of Scytodes sp., an araneophagic spitting spider (Aranae: Scytodidae) from the Philippines. Journal of Zoology (London) 247 (3): 293-310.

LIEN, O.J., FITZGERALD, G.P. 1973. Several factors influencing web-spinning activity in the commom house spider Achaearanea tepidariorum Koch. Animal Learning and Behavior 1(4), 290-292.

LORENZ, K. 1970. The establishment of the instinct concept. In: Studies in animal and human behaviour, vol. 1, Lorenz, K., Harvard University Press.

LUBIN, Y. 1980. The predatory behavior of Cyrtophora (Araneae: Araneidae). J. Arachnol. 8, 159-185.

LUBIN, Y. 1995. Is there division of labour in the social spider Achaearanea wau (Theridiidae)?. Animal Behavior 49(5), 1315-1323. 
LUBIN, Y.D. \& ROBINSON, M.H. 1982. Dispersal by swarming in a social spider. Science 216(4543), 319-321.

MACKAY, W.P. 1982. The effect of predation of western widow spiders (Araneae: Theridiidae) on harvest ants (Hymenoptera: Formicidae). Oecologia (Berl) 53: 406-411.

NOLDUS, L.P.J.J., TRIENES, R.J.H., HENDRIKSEN, A.H.M., JANSEN, H. \& JANSEN, R.G. 2000. The Observer VideoPro: new software for the collection, management, and presentation of time-structured data from videotapes and digital media files. Behavior Research methods, Instruments \& Computers 32, 197-206.

NYFFELER, M. \& BENZ, G.. 1987. Spiders in natural pest control: a review. J. Appl. Entomol. 103:321-339.

NYFFELER, M. 1999. Prey selection of spiders in the field. The Journal of Arachnology 27, 317-324.

NYFFELER, M., DEAN, D. A. \& STERLING, W. L. 1988. The southern black widow spider, Latrodectus mactans (Araneae, Theridiidae), as a predator of the red imported fire ant, Solenopsis invicta (Hymenoptera, Formicidae), in Texas cotton fields. Journal of Applied Entomology 106: 52-57.

PLATNICK, N. 2004. The world spiders catalog, Version 4.0 (online Catalog). Merrett P, Cameron HD, eds. New York: The American Museum of Natural History. http:// research.amnh.org/entomology/

PROCTOR, H.C. 1996. Behavioral characters and homoplasy: perception versus practice. In: Homoplasy: The Recurrence of Similarity in Evolution (M. J. Sanderson \& L. Hufford, eds), pp. 131-149. Academic Press, San Diego.

RIECHERT, S.E. \& LUCZAK, J. 1982. Spider Foraging: Behavioral Responses to Prey. In: P. N. Witt, J. E. Rovner, (eds): Spider Communication: Mechanisms and Ecological Significance. Princeton University Press, Princeton, New Jersey. Pp. 353-385.

ROBINSON, M.H. \& OLAZARRI, J. 1971. Units of behavior and complex sequences in the predatory behavior of Argiope argentata (Fabricius): (Araneae: Araneidae). Smithsonian contributions to Zoology, 65: 1-36.

ROBINSON, M.H. 1969. Predatory behavior of Argiope argentata (Fabricius). Am. Zoologist, 9: 161-173.

ROBINSON, M.H. 1975. The evolution of predatory behavior in araneid spiders. In Baerends, G., Beer, C. \& Mannings, A. (eds.). Function and Evolution of Behavior. Clarendon Press, Oxford, 292-312.

SCHARFF, N. \& CODDINGTON, J.A. 1997. A phylogenetic analysis of the orb-weaving spider family Araneidae (Arachnida, Araneae). Zool.J.Linn.Soc. 120, 355-434.

VALLE,C. \& VALLE, M.T. 1972. Algumas observações sobre a biologia de Metazygia unguiformis. Revista Brasileira de Biologia 32(1), 33-40.
VIERA, C. 1986. Comportamiento de captura de Metepeira sp. A (Araneae, Araneidae) sobre Acromyrmex sp. (Hymenoptera, Formicidae) en condiciones experimentales. Aracnologia, Montevideo, 6: 1-8.

VIERA, C. 1994. Análisis del comportamiento de predator de Metepeira seditiosa (Keyserling) (Araneae, Araneidae) en condiciones experimentales. Aracnologia Suplemento, Montevideo, 8: 1-9.

WISE, D.H. 1993. Spiders in ecological webs. Cambridge. Cambridge University Press. 328pp.

Título: Forrageamento em Achaearanea cinnabarina Levi 1963 (Araneae, Theridiidae) e evolução da caça em aranhas de teia irregular.

Autores: Hilton Ferreira Japyassú \& Eduardo Gonçalves Jotta

Biota Neotropica, Vol. 5 ( número 1a): 2005

http://www.biotaneotropica.org.br/v5n1a/pt/ abstract?article+BN003051a2005

Recebido em 07/12/2003 - Aceito em 01/02/2005

ISSN 1676-0603 


\section{8 - Anexo 1}

Descrição e discussão das categorias comportamentais utilizadas no presente trabalho.

Aproximação: deslocamento (frontal) de aproximação da aranha em direção à presa sem tensionamento dos fios de teia. É anterior à captura propriamente dita ocorrendo, portanto, na fase de detecção. A aproximação geralmente é sucedida por toque ou enrolamento. Viera (1986) descreve uma categoria semelhante denominada “desplazamiento 2", que consiste em um deslocamento da aranha em direção à presa (durante na fase de detecção) o qual pode ser sucedido ou não por um tensionamento do fio.

Busca: a aranha desce até a superfície de captura (geralmente o substrato inferior), tateando-a em várias direções com as pernas anteriores (pendurada nos fios âncora pelas pernas posteriores), na tentativa de encontrar a presa (que geralmene, nestes casos, escapou da sapata adesiva). Esta categoria é geralmente observada após longas fases de detecção, com muitas tentativas de capturas mal sucedidas.

Corte de fios: a aranha pode simplesmente aproximar as quelíceras do fio e realizar o corte, ou ainda trazer o fio com as pernas até as quelíceras para então cortá-lo. Alternativamente a aranha pode arrebentar os fios com flexões bruscas das pernas I. Esta categoria pode ser executada em vários momentos da captura: antes de iniciar o transporte (cortando os fios ao redor da presa), durante o transporte (cortando fios que estão dificultando seu trajeto) ou com a presa no refúgio (Robinson \& Olazarri 1971).

Detecção: movimentos com a região tarsal das pernas anteriores tensionando fios da teia (1-3 mm), com ou sem deslocamento antecedendo tais tensionamentos (Jackson \& Brassington 1987). Esta categoria ocorre no início da captura e tem como função localizar o fio âncora onde a presa está aderida.

Enrolamento de captura: após a aproximação e/ou toque com as pernas I a aranha faz um giro de $180^{\circ}$ e direciona o abdome à presa. Com movimentos alternados das pernas IV, a aranha lança sobre a presa fios de seda com gotículas adesivas, na tentativa de imobilizá-la (a aranha se utiliza do pente na perna IV durante a manipulação destes fios de seda - Coddington 1986). Alternativamente, o enrolamento pode ser feito com movimentos simultâneos (a aranha puxa o fio com uma das pernas IV e, sem o soltar, puxa o mesmo fio com a outra perna, deixando-o paralelo à presa, e com ambas as pernas joga este fio sobre a presa); enquanto isso as pernas III seguram a presa e as pernas I e II se apóiam na teia. O enrolamento de captura é a categoria que delimita o início da fase de imobilização, podendo ocorrer também em outros momentos desta fase e na fase de alimentação, porém com menor freqüência.

Enrolamento: no enrolamento a aranha adota a mesma postura do enrolamento de captura. Neste caso são utilizados fios de seda secos (sem gotículas adesivas). Este tipo de enrolamento apresenta a mesma finalidade do enrolamento descrito por Robinson \& Olazarri (1971) para A. argentata, diferindo apenas pelo volume de fios, que não formam uma bandagem. Na descrição de Robinson \& Olazarri (1971) a aranha pode ainda movimentar a presa como uma bobina, girando-a sobre um raio enquanto lança seda sobre a presa, com ou sem a ajuda das pernas IV; esta variante de enrolamento não ocorre em A. cinnabarina. No presente trabalho não diferenciaremos entre o enrolamento simples daquele com fio viscoso (enrolamento de captura).

Estiramento: após o enrolamento, na fase de imobilização da presa, a aranha pode fixar um fio na presa ou no fio onde a presa se encontra (fixação), após o que ela se desloca em direção ao refúgio, deixando atrás de si um fio guia; a este deslocamento chamamos estiramento. O estiramento pode ocorrer também sem fixação prévia: a aranha interrompe o enrolamento e se desloca diretamente ao refúgio. Após o estiramento a aranha geralmente realiza uma fixação no fio de sustentação ou no refúgio.

Fixação: fixações em fios da teia (a aranha aproxima o abdome de um fio de sua teia, toca-o com as fiandeiras, fixando um novo fio), em fios próximos à presa ou na própria presa.

Fixações com rotação (3fixR): ao chegar ao refúgio a aranha faz fixações e gira o corpo sagitalmente (Robinson \& Olazarri 1971, Viera 1994)

Limpeza: a aranha raspa os apêndices uns nos outros, geralmente aos pares; pode também passar a região tarsal dos apêndices entre as quelíceras; alternativamente, as pernas podem ser raspadas contra o abdome e fiandeiras (Robinson \& Olazarri 1971). A limpeza pode ocorrer nas fases de imobilização e alimentação.

Localização: após imobilizar a presa e dirigir-se até o refúgio, onde pode realizar longas pausas, a aranha, com as pernas anteriores, tensiona lentamente os fios ao seu redor, gira e tensiona novos fios, repetindo o procedimento até que tensione os fios na direção em que a presa está armazenada. Localizada a presa, a aranha se desloca em direção a ela (recuperação).

Manipulação: esta categoria consiste em uma junção de duas categorias já descritas: “toqueteo” (golpes suaves das pernas anteriores e pedipalpos sobre a presa - Viera 1986), e "manipulate" (pequenas mordidas na presa Robinson 1969). A aranha dá vários toques alternados e consecutivos com os palpos sobre a presa, podendo realizar também mordidas curtas. Durante a manipulação a aranha pode percorrer partes do corpo da presa. A manipulação só ocorre após a imobilização da presa.

Mordida curta: inserção e retirada rápida das quelíceras na presa, como se beliscasse a presa (Viera, 1986). A mordida curta pode ocorrer nas fases de imobilização e alimentação e, com grande freqüência, permear a manipulação.

Mordida longa: semelhante à descrição de Viera (1986), esta mordida difere da mordida curta, apenas por seu prolongamento 
no tempo. No presente trabalho não discriminaremos entre os dois tipos de mordida (longa ou curta).

Pausa: assim como a categoria "quietud", descrita por Viera (1986), a pausa corresponde à imobilidade da aranha. Porém, diferentemente de “quietud", a categoria pausa só é registrada após uma quietude com duração igual ou maior a 30 segundos.

Pesca: no lençol ou em um fio âncora (na região próxima ao lençol), a aranha segura com as pernas anteriores o fio âncora onde a presa está aderida e o puxa, com flexões alternadas das pernas I (e ocasionalmente também com as pernas II), de modo a descolar o fio âncora do substrato e trazer a presa para si até que ela esteja entre 1 e $8 \mathrm{~mm}$ de distância, quando então se inicia o enrolamento de captura. Em uma variante, a aranha pode puxar vagarosamente um fio que tenha sido previamente descolado pela presa. A pesca descrita por Japyassú \& Macagnan (no prelo) é diferente da descrição anterior apenas pelo fato de a aranha tensionar as pernas IV ao invés das pernas I e II (para descolar o fio âncora do substrato) e por ocorrer sempre no lençol.

Recuperação: a aranha se aproxima frontalmente (região oral) da presa já imobilizada, para retomar as atividades com esta presa (manipulação, enrolamento, corte de fios ao redor da presa, mordidas). Esta aproximação requer um deslocamento da aranha o qual, quando longo, é freqüentemente permeado por outras categorias, como fixação, limpeza ou toques. Apesar da recuperação proposta por Viera (1994) apresentar o mesmo nome e a mesma função da descrita acima, ela difere bastante na topografia do movimento. Na descrição de Viera a aranha, no refúgio, puxa para si a presa com o auxílio das pernas I e II. Em A. cinnabarina é a aranha que se desloca em direção à presa, a qual pode ou não estar no refúgio.

Remoção: após imobilizar a sua presa, a aranha retorna ao refúgio e, através de manipulações e cortes de fio, retira do lençol/refúgio resíduos de presas anteriores.

Retorno: a aranha desloca-se em direção ao refúgio, sem deixar fio guia. Isto pode ocorrer na fase de detecção, antes do enrolamento de captura, o que caracteriza um erro de localização da presa (Japyassú \& Macagnan em prep.).

Toque: a aranha simplesmente toca na presa com palpos ou pernas (I ou II). Esta categoria geralmente ocorre após aproximação ou recuperação. O toque difere da manipulação, a qual consiste em uma seqüência de toques alternados e consecutivos.

Transporte: após fixar na presa ou após realizar um enrolamento, a aranha desloca-se em direção ao refúgio carregando a presa diretamente nas fiandeiras ou, alternativamente, pendurada nas pernas IV. Robinson \& Olazarri (1971) descrevem dois tipos de transporte: “carry on silk" (igual ao descrito acima) e "carry in jaws", que consiste no transporte da presa nas quelíceras da aranha (não observado em A. cinnabarina). A aranha pode enrolar a presa enquanto a transporta.

http://www.biotaneotropica.org.br 